\title{
MODELO DE GERENCIAMENTO DE PROJETOS PARA APLICAÇÃO NOS CURSOS DE ENGENHARIA
}

\section{MANAGEMENT PROJECT MODEL TO APLICATION IN ENGENEERING COURSES}

\author{
Carlos Roberto Jóia Hozumi ${ }^{1}$; Carlos Alberto Pereira Soares ${ }^{2}$ \\ ${ }^{1}$ Federal Center Technological Education - CEFET- Rio de Janeiro - Brasil \\ carlosrjh@hotmail.com \\ ${ }^{2}$ Federal Fluminense University -UFF - Rio de Janeiro - Brasil carlos.uff@globo.com
}

\begin{abstract}
Resumo
Em pesquisas recentes foram constatadas necessidade de conhecimento do Project Management Body of Knowledge(PMBOK) pelo aluno de engenharia, qualquer que seja sua formação especifica. Este conhecimento leva o profissional de engenharia engajar-se ao mercado de trabalho, trazendo consigo um Certificado de Project Management Professional (PMP). O conhecimento desta ferramenta de trabalho torna-o diferenciado dos demais concorrentes em sua área de atuação. A proposta deste Artigo é apresentar como o PMBOK configura-se na literatura técnica, sua influência no mercado de trabalho e ainda, como um modelo próprio de gestão de projetos pode auxiliar professores, alunos e profissionais do setor, a conduzirem suas tarefas cotidianas.
\end{abstract}

Palavras-chave: PMP; modelo; gestão de projetos.

\section{Introdução}

O modelo de gestão apresentado no corpo deste trabalho é o produto da pesquisa de Tese de Doutorado que os autores desenvolveram e concluíram recentemente na Universidade Federal Fluminense, na linha de pesquisa Sistemas de Gestão, Produção e Qualidade em seu Programa de Pós-Graduação em Engenharia Civil. Este modelo contempla a proposta apresentada na literatura técnica do PMBOK, que é um guia prático para orientação de profissionais que atuam ou pretendem atuar em gerenciamento de projetos em diversos segmentos do trabalho; editado pelo Project Management Institute (PMI), Instituto Americano que tem diversas publicações técnicas orientadas para o gerenciamento de projetos e também para profissionais do setor. Além da literatura, já conhecida por grande parte dos profissionais desta área e de profissionais de ensino e pesquisa, são 
apresentadas as melhores práticas em gerenciamento de projetos que o mercado de trabalho desenvolve em seu cotidiano. Com estes dados, os autores compilaram os resultados em matrizes, desenvolvendo um modelo próprio de gestão de projetos, com proposições de atuação e apresentação de resultados esperados a partir de sua implementação, podendo servir como ferramenta complementar para profissionais interessados neste segmento de trabalho; mercado este que se encontra em grande fase de crescimento e desenvolvimento, sendo fortemente demandado no país e no exterior. A proposta é familiarizar professores de engenharia a este modelo, que poderão aplicá-lo em sala de aulas como ferramenta de auxílio e simulações práticas em gerenciamento de projetos de engenharia, simulando desafios nas nove áreas de conhecimento do PMBOK.

\section{Metodologia da pesquisa}

Após conhecer toda a sistemática do PMBOK, através de curso específico denominado “Aplicações Práticas do PMI”, realizado na Cidade de São Paulo (2005), os autores procederam a uma investigação qualitativa que teve como metodologia uma pesquisa de campo em empresas de gerenciamento de projetos de engenharia civil do Estado do Rio de Janeiro, objeto de pesquisa da Tese “Análise da eficácia dos trabalhos desenvolvidos pelas gerenciadoras de projetos de engenharia civil, sob a ótica dos padrões estabelecidos pelo PMI". Além dos indicadores de eficácia dos trabalhos de gerenciamento de projetos, especificadas nas nove áreas do conhecimento do PMI: integração dos projetos, gestão do escopo, gestão do tempo, gestão do custo, gestão da qualidade, gestão dos recursos humanos, gestão das comunicações, gestão dos riscos e gestão das aquisições, discussões sobre o tema, nas empresas pesquisadas, revelaram um modelo próprio de gestão realizado por estas, em seus projetos de engenharia.

Procurou-se identificar, ou melhor, focar a pesquisa em gerenciadoras de projetos vultuosos, pois os conflitos ou tomada de decisões nestes projetos exigem maior habilidade de seus gestores. Com modelo estatístico de Tagliacarne (1974) quantificou-se a amostra. Assim, 46\% das empresas pesquisadas gerenciam projetos na ordem de US\$ 5.000.001 (cinco milhões e hum dólares) à US\$ 40.000.000 (quarenta milhões de dólares) anuais; e, as demais empresas gerenciadoras (54\%) têm projetos com custos acima de US\$ 40.000.000 (quarenta milhões de dólares). Esta escolha deu-se em virtude de identificarem-se as melhores práticas de gerenciamento por elas desenvolvidas, de forma contribuir para a gestão de projetos de mesma desenvoltura e, principalmente, aqueles de médio e pequeno porte, os quais podem, a partir dos dados apurados, trabalharem de forma sistêmica e eficaz.

O modelo produto desta pesquisa, aplicado em sala de aulas, apresentou grande interesse dos estudantes de engenharia, principalmente daqueles que já se identificam com o perfil de gestor de 
projetos nas empresas de engenharia; área de atuação de 37\% dos engenheiros juniores, $67 \%$ dos engenheiros seniores e 99\% dos engenheiros gerentes (HOZUMI, 2002).

\section{Estado da Arte}

Sabe-se que o PMBOK é um guia prático de conhecimento em gerenciamento de projetos, que serve como ferramenta aos gerenciadores de projetos, não só nos USA como também em grande parte da Europa e da América Latina. O profissional certificado pelo PMI recebe um título de Project Management Professional (PMP) que o habilita atuar em gestão de projetos nas diversas áreas do conhecimento aplicado ao mercado de trabalho, tanto nacional quanto internacional.

$\mathrm{Na}$ França tem se verificado um crescimento na certificação de sistemas de gestão, pelo QUALIBAT ou pela ISO 9000 e outros referenciais setoriais, que são baseados na ISO 9001. Tais referenciais são adaptados em função dos aspectos de cada agente e de seu papel no ciclo produtivo. Segundo Cardoso (2003), o QUALIBAT é o único referencial setorial que prevê a certificação evolutiva, isto é, conforme o desenvolvimento de cada projeto, em cada etapa e especificidade da empresa do setor.

O sistema MPRO Architecte, desenvolvido pelo Centre Scientifique et Technique du Bâtiment, Association Française de l'Assurance Qualité pela Union Nationale des Syndicats Français d'Architects, rege a gestão dos escritórios de arquitetura e engenharia franceses. Seus requisitos são divididos em: elementos permanentes do Sistema de Garantia da Qualidade da empresa e dos elementos específicos de cada projeto. Este documento é analisado por Cardoso (2003) que o divide da seguinte forma:

1) A parte profissional - define os diferentes processos necessários à realização do projeto, considerando as especificidades de cada agente, incluindo medição e monitoramento dos processos produtivos;

2) A parte do cliente - define as exigências do cliente, o retorno de informação deste e a medição da satisfação deste cliente;

3) A parte organizacional - cuida dos aspectos organizacionais tais como: plano de qualidade, manual da qualidade, padronização dos sistemas, documentação, registros, comunicação, recursos financeiros e de RH, formação e aquisição;

4) A parte referente ao comprometimento, análise e melhoria - analisa os mecanismos de evolução da organização e do sistema de gestão de projetos, objetivando melhoria contínua dos fluxos dos processos.

Cardoso (2003) considera que o sistema francês dedica uma menor importância ao comprometimento, análise e melhoria da organização ou da eficiência. Em sua opinião, isto ocorre 
porque a certificação profissional na França é voluntária, não havendo o poder de compra do Estado e nem a atuação de órgãos públicos que definam modelos a serem adotados pelos referenciais. Fica a cargo da empresa a opção pela implementação de mecanismos de melhoria dos Sistemas de Gestão de Projetos ou implementação da Gestão da Qualidade.

Na Itália, Pietroforte e Tangerini (1999) fizeram uma pesquisa com as cinqüenta maiores empresas durante os anos oitenta e noventa. Estes autores concluíram que o mercado italiano é regido por relações informais, com agências estatais ineficientes, com profissionais de gestão de projetos apresentando deficiências técnicas e que as empresas de construção civil detêm a liderança na condução dos empreendimentos.

Garaventa (1992) destacou, ainda, que o desenvolvimento de normas técnicas para produção industrial tradicional só é realizado para os casos em que o proprietário é conhecedor da regulamentação técnica. A certificação técnica para gestão da qualidade é limitada a poucos produtos. No entanto, a qualidade na gestão de projetos e na gestão da qualidade teve um grande avanço nos últimos anos, principalmente, pela difusão de novos processos e projetos. Para a criação de um novo produto, onde se necessita de certificação da qualidade, submete-se ao controle técnico feito pelo Instituto Central para Industrialização e Tecnologia da Construção (ICITE) que atua na área de ensaios de materiais e controle da qualidade. Porém, sua atuação é limitada.

A certificação da gestão dos processos e em especial da qualidade na Itália tem aumentado nos últimos anos, apresentando requisitos mínimos a partir de 2003. Desde 2005 estas exigências foram impostas a todas as empresas do setor, exceto às organizações de pequeno porte.

Na Dinamarca, ao estudar a implantação de um sistema de gestão de projetos e gestão da qualidade, Thygesen (1989) concluiu que a implantação destes é apenas parte do aperfeiçoamento dos sistemas dos processos, realizadas em conjunto com a aplicação do gerenciamento dos recursos humanos e utilização extensa de tecnologia da informação nas práticas de projeto. Afirmou, ainda, que a cooperação é o principal conceito a ser difundido nas organizações.

O Ministério de Habitação e Assuntos Relativos a Urbanização dinamarquesa desenvolveu a partir de 1998, em conjunto com empresas, pesquisadores e usuários, um programa de melhores formas de cooperação em sistemas produtivos. Este programa foi aplicado em dez empreendimentos locais, observando-se relevante melhoria ao produto final.

Olsen (2001), também, concorda que a cooperação entre os agentes é fator essencial para obtenção de melhores resultados com aumento da qualidade, produtividade e satisfação profissional. O autor explicita, ainda, que devem ser otimizadas as atividades relativas ao envolvimento dos recursos humanos internos ou sub-contratados, utilizando equipes multidisciplinares nos canteiros de obra, além de adequarem seus sistemas baseando-se em benchmark realizados, para melhoria de seus processos de trabalho. É recomendado que a seleção 
do construtor seja feita desprezando-se o critério de menor preço, mas sim que seja baseada em sua experiência profissional, qualificação e capacitação.

Na Grã-Bretanha, foi feito um estudo, conduzido por Moatzed-Keivani et al (1999), com gestores de projetos em doze das principais empresas de construção do país, para determinar a percepção sobre a certificação da qualidade e sistemas de gestão de projetos. Através deste estudo, concluiu-se que o requisito do cliente e a estratégia de marketing foram os principais motivadores para a certificação da qualidade em um sistema de gestão. Os resultados mais importantes obtidos foram: a melhoria da estrutura de gestão e a conscientização do pessoal. Porém, esses gestores acham que precisa-se melhorar os sistemas aplicados a indústria de construção civil, em especial a coordenação entre os departamentos e as etapas de construção em seus processos produtivos.

Desenvolveu-se então pesquisa com setecentas organizações. Havia um pequeno percentual de empresas com certificação da qualidade no mercado, cerca de $17 \%$ e que as principais razões para a certificação foram: a pressão dos consumidores, aumento da eficiência e produtividade, melhoria do produto e da imagem da empresa no mercado. Na Grã-Bretanha ocorrem muitas mudanças de projeto durante a fase de construção, acarretando a ocorrência de muitos problemas no canteiro de obras, devido a gestão dos projetos não serem padronizados.

Nos Estados Unidos, a prática é buscar o aumento da eficiência e a velocidade na construção com obras rápidas e objetivando sempre a minimização do custo, já dizia Bennett, (1991). O sucesso do empreendimento decorre da competência de seu gestor, utilizando-se de procedimentos e padrões pré-definidos na concepção do projeto, além do uso e entendimento das novas tecnologias. Estes fatos ratificam as diferenças de produtividade entre as construtoras americanas e as brasileiras, segundo McKinsey (1998).

A construção americana é de baixo custo e com alto grau de mecanização, padronização, pré-fabricação e muito pouca variação no projeto; ao contrário da industria brasileira. A padronização envolve a produção em massa, aumentando desta forma a eficiência. Os préfabricados aumentam a segurança, qualidade e eficiência (XIAO, 2002).

Nos Estados Unidos, os conceitos de sistemas de gestão de projetos são mais difundidos. Para o êxito desta filosofia é necessário que as práticas de gestão estejam bem definidas, de acordo com os métodos de gerenciamento interno do empreendimento, conciliando as muitas atividades presentes em um sistema de gestão.

O documento da American Society of Civil Engineers (2000) aborda os passos para a garantia da qualidade das construções com destaque especial para a responsabilidade do construtor (gestor) já que, de acordo com este documento é ele que deve ter a liderança sobre as atribuições e particularidades dos outros intervenientes. 
Um modelo de avaliação chamado "CQP- Contractor Quality Performance" é proposto por Yasamis, Arditi e Mohammadi (2002), para avaliação dos gestores do projeto. Têm-se como parâmetros desta mensuração a qualidade, a satisfação do cliente, o desempenho e a inter-relação entre agentes do projeto realizado.

O PMI vem de encontro a atender as expectativas expostas para os projetos de engenharia civil no Brasil principalmente em empresas certificadas estatais e privadas, tendo no PMBOK uma ferramenta útil ao bom desenvolvimento dos trabalhos nas nove áreas de conhecimento por ele descrito.

\section{Análise qualitativa dos dados da pesquisa}

Analisando as argumentações dos gestores de projetos nas empresas gerenciadoras de projetos pesquisadas, destacam-se relevantes questões a respeito dos indicadores encontrados e sua aplicabilidade prática como resultado do trabalho.

O MS PROJECT é o programa de gerenciamento mais usual (100\%), entre as empresas gerenciadoras de projetos de engenharia civil. É compreensível tal escolha por parte dos gestores, pois, este programa gerencia prazos e custos, além de recursos humanos essenciais ao cumprimento das tarefas a serem executadas. Ele proporciona ainda, de forma fácil, redimensionar equipe e gerenciar folgas ou atrasos previstos no planejamento. Este veio substituir o velho PERT (Program Evoluation and Review Techinique), o qual, era elaborado na década de 1970 a 1980 de forma manual dando imenso trabalho aos gestores de projetos da época.

O programa PRIMAVERA (50\%) e também do modelo PMBOK (11\%) são conhecidos e utilizados no cotidiano dos gerenciadores de projetos. Muitas empresas têm seus próprios sistemas de gestão de projetos, com procedimentos internos que contribuem para o sucesso de seus negócios. Praticam reuniões gerenciais com freqüência e ainda, utilizam dados estatísticos de ações corretivas e preventivas, além de análises empíricas de trabalhos anteriores por elas desenvolvidas, para obterem resultados eficazes em seus gerenciamentos de projetos.

O processo de gestão de projetos é dinâmico (43\% das gerenciadoras consideram esta afirmativa), desta forma, não se tem muito tempo de implementar novas tecnologias. Falta de recursos em um determinado empreendimento constitui-se em dificuldade para continuidade dos trabalhos contratados. A falta de feedback dos executores dos projetos prejudica a atualização de indicadores produtivos; desta forma, questões ou problemas sem respostas rápidas dificultam a eficácia dos trabalhos de gerenciamento. 
Outro aspecto que cria grande dificuldade na gestão dos projetos é a indefinição desses projetos que, com constantes alterações e complementações induzem a gastos extras e prazos complementares.

A gestão de projetos tem como objetivo principal a redução dos erros executivos na opinião de $68 \%$ dos gestores entrevistados. Não menos relevantes tem-se na redução dos custos (19\%), na satisfação dos stakeholders (7\%) e ainda, na redução dos riscos do projeto (4\%), objetivos que complementam o trabalho das gerenciadoras de projetos de engenharia civil.

Os trabalhos de gerenciamento de projetos têm por objetivo principal a redução dos erros do projeto que, por conseguinte, promovem redução expressiva nos seus custos executivos: até 6\% de redução para $25 \%$, de $6 \%$ a $8 \%$ de redução para $57 \%$ e acima de $8 \%$ chegando até $20 \%$ de redução desses custos para $18 \%$ dos gestores pesquisados. Conclui-se, desta forma, que o gerenciamento de projetos traz vantagens financeiras aos empreendedores.

Os resultados mostram a inabilidade e o desconhecimento do PMBOK por parte de seus gestores pesquisados. Com esses dados, a implementação desta metodologia nos cursos de engenharia civil torna assunto em pauta de discussões; de forma, familiarizar o aluno a esta ferramenta gerencial, a qual poderá facilitar seu ingresso neste mundo de trabalho em amplo crescimento e desenvolvimento.

As empresas apresentam, de uma forma geral, desempenho eficaz em seus trabalhos de gerenciamento de projetos de engenharia civil, comprovando-se desta forma a eficácia dos trabalhos de gerenciamento desenvolvidos pelas empresas gerenciadoras de projetos, sob a ótica dos padrões estabelecidos pelo Project Management Institute.

Pretende-se com esta análise apresentada, dar início a novos estudos sobre o tema, possibilitando aos pesquisadores terem um instrumento capaz de servir de base para novos estudos e desenvolvimento no setor de engenharia civil.

\section{Modelo de gerenciamento de projetos para aplicação nos cursos de engenharia}

Investimentos na melhoria da qualidade em gestão dos processos nos projetos têm sido apontados como vitais por muitos autores, pesquisadores e empreendedores ligados ao setor de engenharia civil em todo mundo, em função dos impactos que cada fase possui sobre todas as outras do processo produtivo. Nesse contexto, o presente modelo trata de descrever práticas pró-ativas, contribuindo para melhoria nos relacionamentos dos stakeholders, aqueles envolvidos na gestão dos projetos de engenharia. Essas iniciativas envolvem desde mudanças à implementação de novas metodologias de gestão em cada fase do projeto e, especialmente, na sistematização de informações para o seu desenvolvimento. 
A partir do estudo de modelos representativos desenvolvidos por autores nacionais, citado por Fontenelle (2002), para o fluxo de desenvolvimento do processo de projeto, pode-se dizer que qualquer tentativa de melhoria na gestão desses processos deve partir, ao menos inicialmente, do estabelecimento ou escolha de um fluxo-base que atenda aos interesses e necessidades de todos os intervenientes envolvidos, e globais do empreendimento. Dentro dessa premissa, apresenta-se uma proposta composta das melhores práticas pró-ativas, na gestão de projetos, adotadas em cada fase do processo de gestão de projetos pelas empresas do setor de engenharia civil, tendo como fluxobase os procedimentos descritos no Project Management Body of Knowledge (PMBOK), para as nove áreas do conhecimento do gerenciamento de projetos.

O Modelo apresenta as melhores práticas em gerenciamento de projetos de engenharia civil, onde o professor pode simular determinada situação "real" para solução, pelo aluno, das melhores alternativas a seguir, traçando diretrizes condizentes com o que o mercado de trabalho executa, com o que o autor sugere e a partir daí, que resultados podem ser alcançados ou esperados, a partir de sua implementação. A aula torna-se altamente dinâmica e produtiva, com indicadores reais e ainda, criativos, que possibilitam ao professor orientar o caminho mais adequado que o aluno deve seguir, lapidando sua atuação profissional desde sua formação acadêmica.

Sabe-se que o PMBOK distribui seus fluxos de processos em nove áreas do conhecimento. Para este Artigo, apresento o modelo aplicado em três dessas áreas: Integração dos Projetos, Gestão do Escopo e Gestão do Tempo nos projetos de engenharia civil. Pode-se obter o complemento deste modelo através da Tese de Doutorado do primeiro Autor ou através do e-mail: carlosrjh@hotmail.com, onde disponibilizo informações complementares deste estudo.

\section{O MODELO}

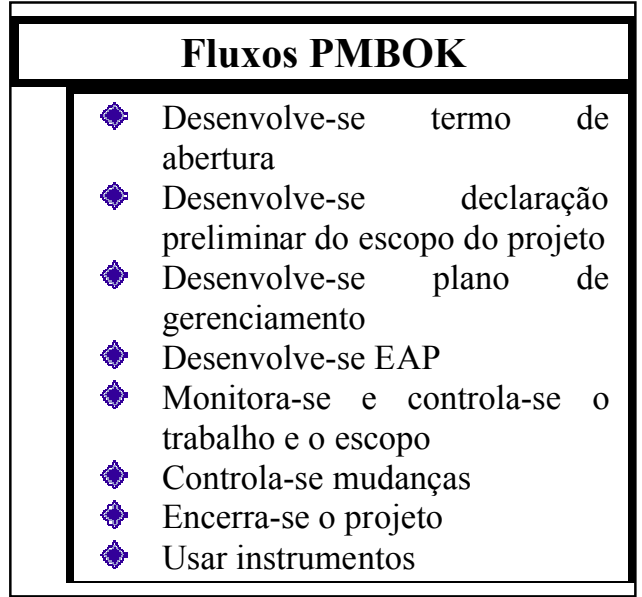

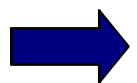

\begin{tabular}{|l|}
\hline \multicolumn{1}{|c|}{ Perfil do Mercado } \\
\hline $100 \%$ das empresas realizam termo de abertura \\
do projeto; \\
$89 \%$ destas, recomendam mensurar o tamanho \\
do empreendimento para verificarem-se \\
necessidades atreladas a execução; \\
$\begin{array}{l}96 \% \text { ordenam as tarefas e funções executivas } \\
\text { do projeto }\end{array}$ \\
$93 \%$ planejam as etapas executivas do projeto \\
antecipadamente; \\
$96 \%$ fazem planilhas de controle e \\
desempenho; \\
$86 \%$ integram as etapas, prevendo mudanças; \\
$93 \%$ encerram o projeto checando o \\
cumprimento de todas as etapas executivas do \\
projeto; \\
$100 \%$ usam sistemas próprios de gestão, como \\
instrumento de trabalho.
\end{tabular}


Figura 1 - Processos para realizar Integração do Projeto pelo PMI e por Empresas de Mercado

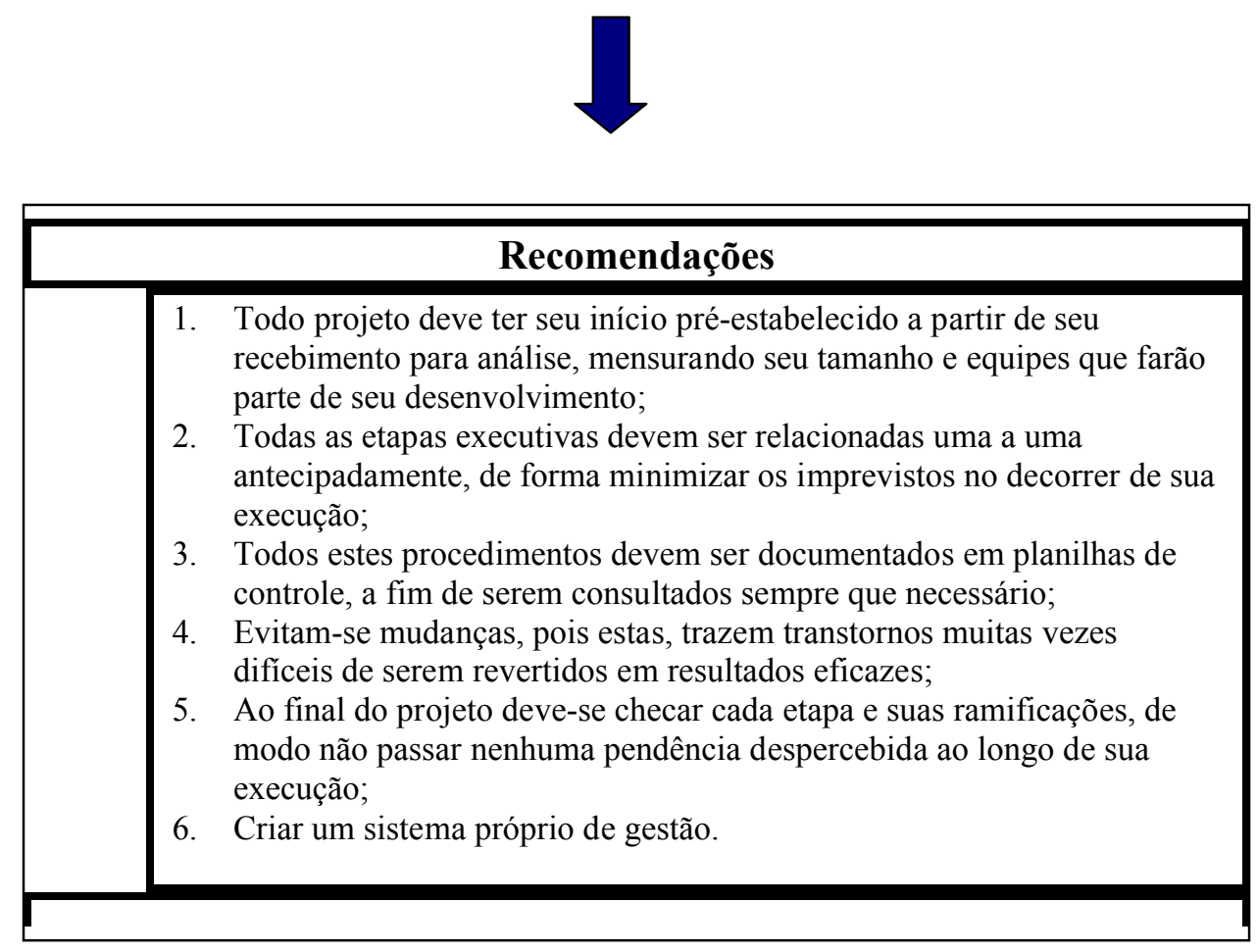

Figura 2 - Recomendação dos Autores para realizar Integração do Projeto

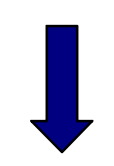

\section{Resultados / Expectativas Pró-Ativas executivas}

Quanto mais detalhadas as etapas executivas do projeto menos riscos, imprevistos e erros executivos são cometidos, reduzindo-se, desta forma, custos e tempos extras ao projeto;

Criar um roteiro padronizado pode garantir ganho de tempo e incertezas na realização de novos projetos;

O dinamismo executivo fica diretamente ligado à eficácia executiva de cada etapa do processo. Fato proporcionado pela organização gerencial na integração dos projetos;

Esperam-se resultados eficazes de integração do projeto, a partir da criação de um sistema próprio de gestão que controle todas as etapas do projeto.

Figura 3 - Resultados esperados a partir das recomendações na Integração do Projeto 


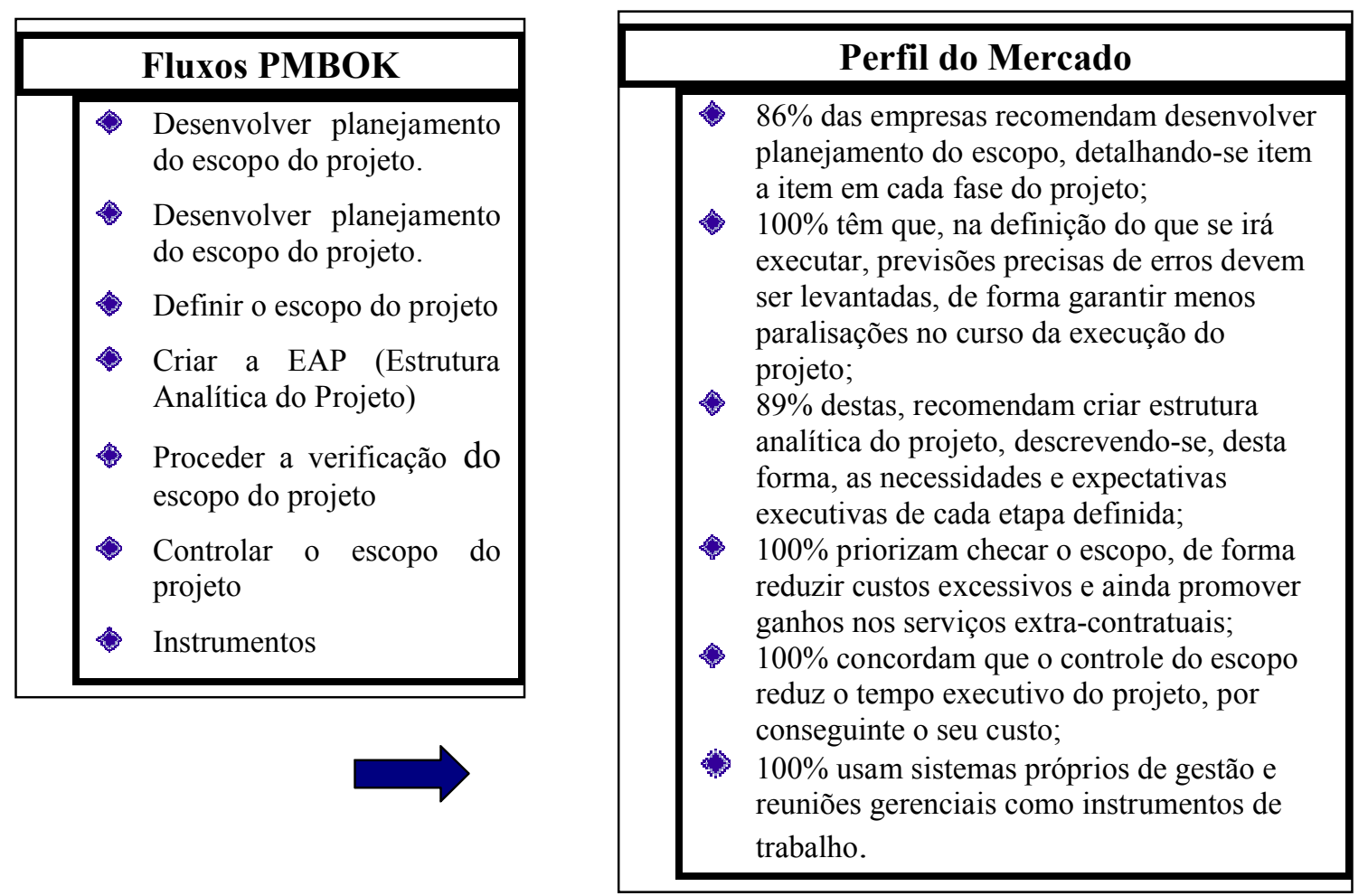

Figura 4 - Processos para realizar Gestão do Escopo do Projeto pelo PMI e por Empresas de Mercado

\begin{tabular}{|l|}
\hline \multicolumn{1}{|c|}{ Recomendações } \\
\hline 1. \\
Todo projeto deve ser detalhado item a item objetivando-se determinar o \\
quantitativo de serviços, materiais e equipamentos que, junto a mão de obra \\
necessária, irão compor o escopo definitivo do projeto; \\
2. Todas as etapas executivas devem ser relacionadas e planejadas, uma a uma, \\
antecipadamente, de forma minimizar os imprevistos no decorrer de sua execução; \\
Todos estes procedimentos devem ser documentados em planilhas de controle, a \\
fim de serem consultados sempre que necessário. Ações preventivas e corretivas \\
reduzem erros e tempo de execução do projeto; \\
4. Deve-se evitar e controlar mudanças, pois estas, trazem transtornos muitas vezes \\
difíceis de serem revertidos em resultados eficazes; \\
Ao final do projeto deve-se checar cada etapa e suas ramificações, de modo não \\
passar nenhuma pendência despercebida ao longo de sua execução; \\
Criar um sistema próprio de gestão e promover constantes reuniões gerenciais, de \\
forma estreitar as expectativas, dificuldades e soluções para o projeto.
\end{tabular}

Figura 5 - Recomendação dos Autores para realizar Integração do Projeto 


\section{Resultados / Expectativas Pró-Ativas executivas}

Q Quanto mais detalhadas as etapas e o escopo do projeto menos riscos, imprevistos e erros executivos serão cometidos, reduzindo-se, desta forma, custos e tempos extras ao projeto;

- Criar uma estrutura analítica padrão do projeto garantindo ganho de tempo e riscos na realização de novos projetos, embora sabe-se que cada projeto é único de características específicas e próprias;

○ dinamismo executivo fica diretamente ligado à eficácia executiva de cada etapa do processo. Fato proporcionado pela organização gerencial na gestão do escopo do projeto;

- Esperam-se resultados eficazes de gestão do escopo do projeto, a partir da criação de um sistema próprio de gestão e interação de todos aqueles envolvidos no planejamento e controle de todas as etapas do projeto.

Figura 6 - Resultados esperados a partir das recomendações de Gestão de Escopo do Projeto

\begin{tabular}{|l|l|}
\hline \multicolumn{1}{|c|}{ Fluxos PMBOK } \\
\hline & $\begin{array}{l}\text { Definir as atividades do projeto } \\
\text { Desenvolver a seqüência de } \\
\text { atividades do projeto }\end{array}$ \\
$\ominus$ & $\begin{array}{l}\text { Estimativa de recursos das } \\
\text { atividades do projeto }\end{array}$ \\
$\ominus$ & $\begin{array}{l}\text { Estimativa de duração das } \\
\text { atividades do projeto }\end{array}$ \\
Desenvolver o cronograma do \\
projeto \\
Controlar o cronograma do \\
projeto \\
Instrumentos
\end{tabular}

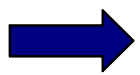

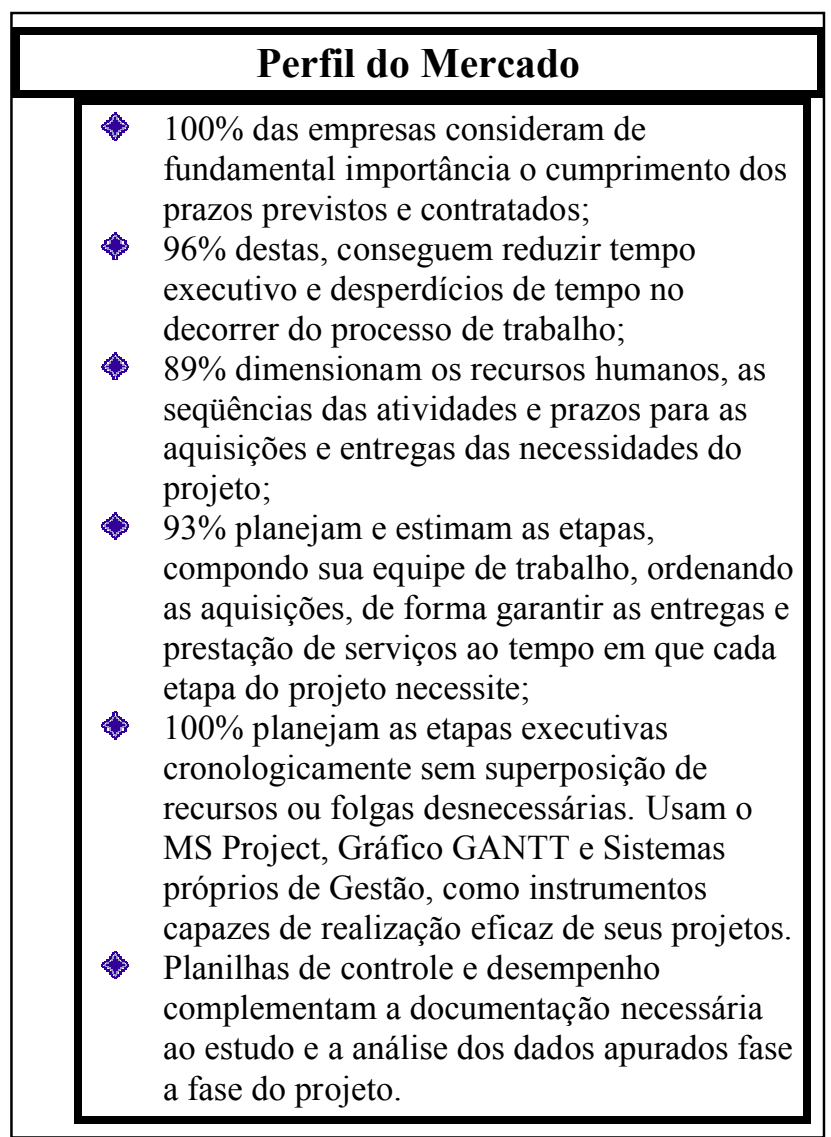

Figura 7 - Processos para realizar Gestão do Tempo do Projeto pelo PMI e por Empresas de Mercado

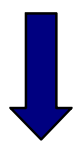




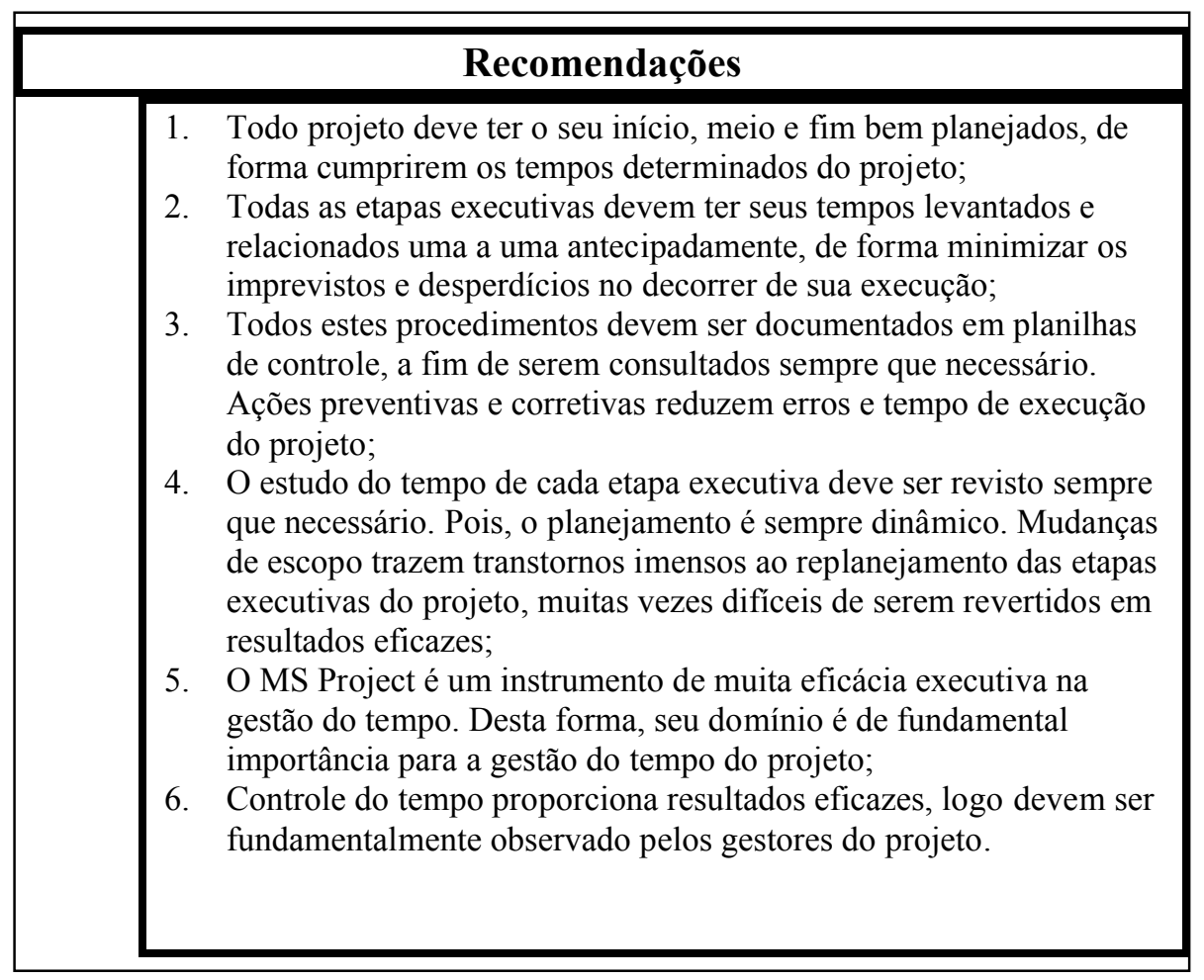

Figura 8 - Recomendação dos Autores para realizar Gestão do Tempo do Projeto

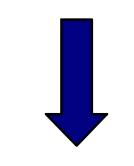

\section{Resultados esperados / Expectativas Pró-Ativas executivas}

$\diamond$ Quanto mais detalhadas as etapas executivas do projeto menos riscos, imprevistos e erros executivos com relação ao tempo são cometidos;

$\diamond$ Criar um roteiro padronizado de ações pode garantir ganhos executivos na realização de novos projetos;

\& A eficácia executiva na gestão do tempo, em cada etapa do projeto, proporciona custos reduzidos e satisfação dos clientes;

- Esperam-se resultados eficazes de gestão do tempo, a partir da criação de um sistema próprio de gestão que controle todas as etapas do projeto;

$\diamond$ O cumprimento dos prazos do projeto garante novos negócios e lucros às empresas.

Figura 9 - Resultados esperados a partir das recomendações de Gestão do Tempo do Projeto

\section{Conclusão}

Afirmando-se que "são eficazes os trabalhos desenvolvidos pelas empresas gerenciadoras de projetos sob a ótica dos padrões estabelecidos pelo Project Management Institute", hipótese esta, satisfeita e comprovada pelos indicadores de desempenho apurados pela tese de doutorado do autor 
(figura 10), pôde-se reconhecer no PMBOK uma ferramenta de apoio ao gerenciamento de projetos e que este proporciona vantagens aos trabalhos de seus gestores; não sendo a única, mas, certamente, uma base de estudos para o tema proposto.

\begin{tabular}{|l|c|}
\hline Área do Conhecimento PMI & desempenho e eficácia \\
\hline Integração de Projetos & $88 \%$ \\
\hline Gestão do Escopo & $86 \%$ \\
\hline Gestão do Tempo & $92 \%$ \\
\hline Gestão do Custo & $95 \%$ \\
\hline Gestão da Qualidade & $86 \%$ \\
\hline Gestão dos Recursos Humanos & $88 \%$ \\
\hline Gestão das Comunicações & $89 \%$ \\
\hline Gestão dos Riscos & $82 \%$ \\
\hline Gestão das Aquisições & $90 \%$ \\
\hline
\end{tabular}

Figura 10- Eficácia das empresas pesquisadas em gestão de projetos

Como instrumento informatizado de gestão encontrou-se no MS Project uma ferramenta que, agregada a sistemas próprios de gestão, proporciona praticidade, velocidade, precisão e eficácia na gestão de projetos nas nove áreas de conhecimento estabelecidas pelo PMI.

Quando se pensa em produtividade no setor de gerenciamento de projetos em outros países, consideram-se aspectos e características típicos de cada país ou região onde se realizam os trabalhos de gestão de projetos de engenharia civil. Cada região tem sua tecnologia e tipicidade própria de produção. Mão de obra especializada é valor agregado à produtividade. Paises com menos mão de obra qualificada traz custos imediatos mais baratos; porém, em longo prazo, produtos de mais qualidade e tecnologia mais avançada tem menos re-trabalho e perdas, além de credibilidade e resultados de investimentos mais eficazes. Por estas e outras razões complementares é que se propõe treinar o alunado para enfrentar os desafios impostos em seu mercado de trabalho.

Os processos e técnicas de gerenciamento de projetos de engenharia, sob a ótica dos padrões estabelecidos pelo PMI, inclui vários procedimentos e fluxos necessários à sua realização eficaz; de especial aplicação na engenharia civil. Esses procedimentos apresentados no corpo deste trabalho tornaram-se diretrizes de orientação em pesquisas, como uma ferramenta auxiliar aos gestores de projetos de engenharia.

Os resultados e indicadores extraídos da pesquisa de tese do autor possibilitaram a elaboração deste modelo pró-ativo que contempla as melhores práticas de gerenciamento de projetos de engenharia civil. Esta ferramenta vem com intuito de contribuir para a execução dos trabalhos de pequenas e médias empresas do setor, além de servir como instrumento de trabalho para o professor nas salas de aulas, simulando situações reais para capacitar o aluno em seu cotidiano profissional. 
Estudos complementares deverão ser elaborados para aperfeiçoamento do modelo apresentado por este artigo, já aplicado com sucesso no segmento educacional de algumas instituições de ensino; porém, é apenas um passo inicial de incentivo a novas pesquisas que possam preparar melhor o aluno de engenharia ao mercado de trabalho demandado atual.

\section{Referências}

AMERICAN SOCIETY OF CIVIL ENGINEERS-ASCE. Quality in the constructed project: a guide for owners, designers and constructors. Reston, VA, 2000.

ASSOCIAÇÃO BRASILEIRA DE NORMAS TÉCNICAS-(ABNT). NBR ISO 9001:2000. Gestão da Qualidade. Normas. Rio de Janeiro,2004.

BENNET, J. International construction project management: general theory and practice. Oxford: Butterworth Heinemann, 1991.

CARDOSO, F.F. Certificações profissionais do setor de edificações na França e aprendizados para o Brasil. In: III SIMPÓSIO BRASILEIRO DE GESTÃO E ECONOMIA DA CONSTRUÇÃO- SIBRAGEC III -2003, São Paulo, Anais...UFSCAR,São Carlos, 16 a 19 set. 2003.

FONTENELLE, E.C. Estudos de caso sobre a gestão do projeto em empresas de incorporação e construção. Dissertação de Mestrado - Escola Politécnica. Universidade de São Paulo. São Paulo, 2002.

GARAVENTA, S. Incidence du faible développement de la reglementationdans le secteur du bâtiment em Italie: conséquences techniques et organisationelles, relazione al Colloque Europe et Chantiers, Plan construction et CEREQ, Paris 28,29 et 30 septembre 1988, in Europe et Chantiers: structures industrielles et marché du travail des acts du colloques des 28 et 29 septembre 1988, PCA, Paris, 1992.

HOZUMI, C.R.J. As Transformações no Mundo do Trabalho e a Atuação do Engenheiro Industrial. Dissertação de Mestrado, Centro Federal de Educação Tecnológica - CEFET-RJ, 2002.

. , Análise da Eficácia dos Trabalhos Desenvolvidos pelas Gerenciadoras de Projetos de Engenharia Civil, sob a Ótica dos Padrões estabelecidos pelo Project Management Institute. Tese de Doutorado, Universidade Federal Fluminense - UFF, 2006.

MCKINSEY GLOBAL INSTITUTE. Produtividade: a chave do desenvolvimento acelerado no Brasil. São Paulo, Mckinsey Brasil,1998 (relatório)

MOATAZED-KEIVANI, R.\& GHANBARI-PARSA, A.R. ISO 9000 standards; perceptions and experiences in the UK construction industry. Construction Management and Economics. London,v.17,p.107-119, 1999.

cross

OLSEN, I.S. The cooperation of the future in the melting pot. In WORLD BUIDING CONGRESS CIB PERFORMANCE IN PRODUCT AND PRACTICE. Wellington, 2001. Proceedings. Wellington, New Zealand.

PIETROFORTE, R. \& TANGERINI, P. From boom to bust; the case of Italian construction firms. Construction Management and Economics, London,v.17,n.4,p.419-425,1999.

cross ${ }^{\text {ref }}$

PMBOK. A guide to the Project Management Body of Knowledge. Newton Square: Project Management Institute, 2004.

TAgliacARne, G. Pesquisa de Mercado: Técnica e Prática. São Paulo, Atlas. Ed. da Universidade de São Paulo, 1974

THYGESEN, T. Implementation of control methods and procedures within an architectural firm. In: SEMINAR EOQC CONSTRUCTION SECTION HELD, Copenhagen Denmark, Proceedings. Copenhagen: Technological Institute, n.6,p.27-29, 1989. 
XIAO, H. \& PROVERBS, D. The performance of contractors in Japan, the UK and the USA; an evaluation of construction quality. International Journal of quality \& Reliability Management. Bradford,v.19,n.6,p.672-687,2002.

YASAMIS,F; ARDITI D.\% MOHAMMADI, J. Assessing contractor quality performance. Construction Management and Economics. London, v.20, n.3, p.211-223, 2002.

cross

\begin{abstract}
In recent research they had been evidenced necessity of knowledge of the Project Management Body of Knowledge (PMBOK) for the engineering pupil, any that is its specific formation. This knowledge takes the engineering professional to engage it the work market, bringing obtains a Certificate of Project Management Professional (PMP). The knowledge of this tool of work becomes differentiated it of the excessively competing ones in its area of performance. The proposal of this Article is to present as the PMBOK configures in literature technique, its influence in the work market and still, as a proper model of management of projects can assist professors, pupils and professionals of the sector, to lead its daily tasks.
\end{abstract}

Key-words: PMP; model; management of projects.

\title{
Dados dos autores:
}

Nome completo: Carlos Roberto Jóia Hozumi

Filiação institucional: CEFET-RJ

Departamento: Construção Civil

Função ou cargo ocupado: Professor Efetivo

Endereço completo para correspondência : Av. Maracanã 229, Rio de Janeiro, RJ, Brasil. CEP: 20.271-110

Telefones para contato: (21) 2566-3022 / (21) 9113-2013

E-mail: carlosrjh@hotmail.com

Nome completo: Carlos Alberto Pereira Soares

Filiação institucional: UFF

Departamento: Engenharia Civil

Função ou cargo ocupado: Professor Adjunto

Endereço completo: Rua Passo da Pátria, 156, São Domingos, Niterói, RJ CEP: 24210-240

Telefones para contato: (21) 2629-5412 / (21) 9764-7478

E-mail: carlos.uff@globo.com

Recebido para publicação em: 27/09/2007

Aceito para publicação em: 30/10/2007 